Published in final edited form as:

Anal Chem. 2020 June 02; 92(11): 7683-7689. doi:10.1021/acs.analchem.0c00573.

\title{
Photostable and Proteolysis-Resistant Förster Resonance Energy Transfer-Based Calcium Biosensor
}

\author{
Dat Nguyen ${ }^{£}$, Danielle M. Behrens ${ }^{£, \Psi}$, Sanjana Sen ${ }^{¥}, \Psi$, Avid Najdahmadi ${ }^{\dagger}$, Jessica N. \\ Pham $^{\dagger}$, Gaetano Speciale ${ }^{\dagger}$, Micah M. Lawrence ${ }^{£}$, Sudipta Majumdar ${ }^{\dagger}$, Gregory A. \\ Weiss ${ }^{\dagger,}, \beta,{ }^{*}$, Elliot L. Botvinick ${ }^{£, t, \xi},{ }^{*}$ \\ EDepartment of Biomedical Engineering, University of California, Irvine, CA 92697-2730 USA. \\ ${ }^{\sharp}$ Department of Molecular Biology \& Biochemistry, University of California, Irvine, California \\ 92697-3900, USA. \\ 'Beckman Laser Institute and Medical Clinic, University of California, Irvine, CA 92612-1475, USA \\ tDepartment of Chemistry, University of California, Irvine, Irvine, California 92697-2015, USA \\ ${ }^{\beta}$ Department of Pharmaceutical Sciences, University of California, Irvine, California 92697-4625, \\ USA. \\ §Department of Surgery, University of California, Irvine, CA 92697-2730, USA.
}

\section{Abstract}

Molecular sensors from protein engineering offer new methods to sensitively bind to and detect target analytes for a wide range of applications. For example, these sensors can be integrated into probes for implantation, and then yield new and valuable physiological information. Here, a new Förster Resonance Energy Transfer (FRET)-based sensor is integrated with an optical fiber to yield a device measuring free $\mathrm{Ca}^{2+}$. This membrane-encapsulated optical fiber (MEOF) device is composed of a sensor-matrix that fills polytetrafluoroethylene (PTFE) with an engineered Troponin $\mathrm{C}(\mathrm{TnC})$ protein fused to a pair of FRET fluorophores. The FRET efficiency is modulated upon $\mathrm{Ca}^{2+}$ ion binding. The probe further comprises a second, size-excluding filtermembrane that is synthesized by filling the pores of an PTFE matrix with a polyethylene glycol dimethacrylate (PEGDMA) hydrogel; this design ensures protection from circulating proteases and the foreign body response. The two membranes are stacked and placed on a thin, silica optical fiber for optical excitation and detection. Results show the biosensor responds to changes in $\mathrm{Ca}^{2+}$ concentration within minutes with a sensitivity ranging from 0.01 to $10 \mathrm{mM} \mathrm{Ca}^{2+}$, allowing discrimination of hyper and hypocalcemia. Furthermore, the system reversibly binds $\mathrm{Ca}^{2+}$ to allow

\footnotetext{
“Corresponding Authors; elliot.botvinick@uci.edu Elliot Botvinick, gweiss@uci.edu Gregory Weiss.

Contributed equally

Author Contributions

The manuscript was written through contributions of all authors. All authors have given approval to the final version of the manuscript.

Supporting Information

Supporting Information Document (PDF) - The document contains additional material that supports the findings of the study. This includes the nucleotide sequence and plasmid map of STC, hydrogel swelling dynamics, construction of the spectroscopic benchtop system, GFP encapsulation by the MEOF probe, selective permeability of the filter-membrane, Twitch-2B photobleaching, protein and fluorescent gels of STC after expression, illustration of Alexa Fluor dye conjugation onto STC, and STC unbinding of Ca ${ }^{2+}$.

The authors declare no competing financial interest.
} 
continuous monitoring. This work paves the way for the use of engineered structure-switching proteins for continuous optical monitoring in a large number of applications.

\section{Graphical Abstract}

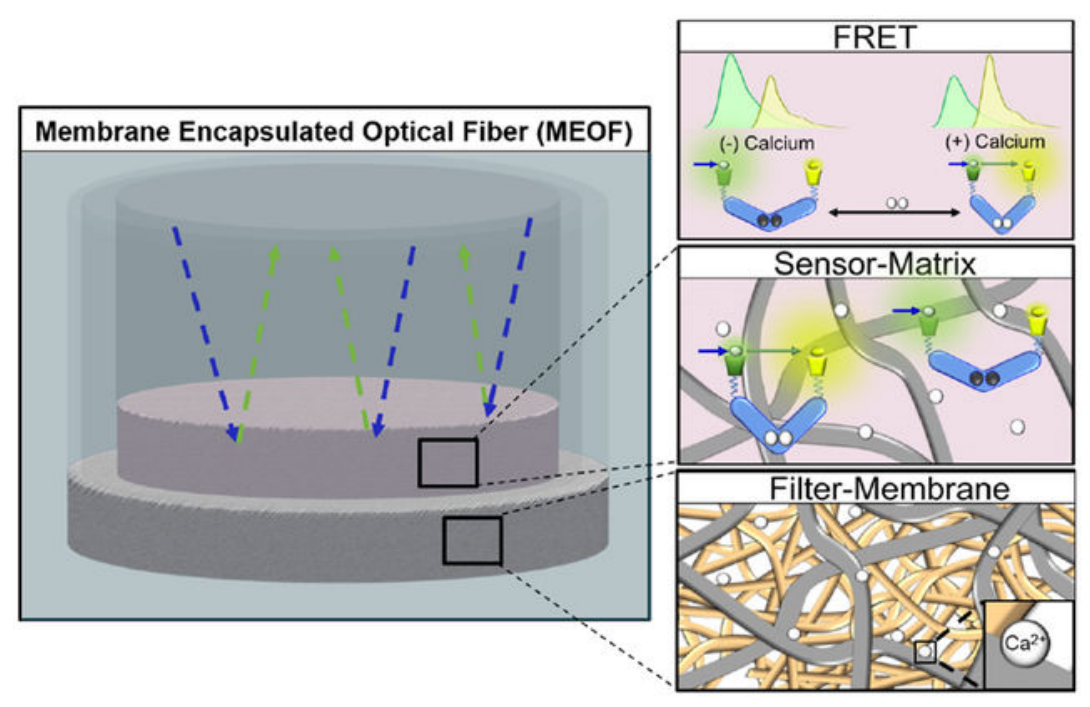

The development of continuous biomedical sensors provides clinicians and researchers realtime data on clinically relevant and new physiological signals. ${ }^{1}$ Currently, the catalog of continuous sensors is vastly outweighed by the number of clinically relevant analytes, which are largely analyzed with point-of-care (POC) devices or at clinical laboratories. For example, ionized calcium $\left(\mathrm{Ca}^{2+}\right)$, an essential mineral for muscle contraction, bone development, nerve impulses, blood clotting, and regulating heart beat propagation, is assayed by a calcium blood test; this test requires a healthcare professional to draw blood from a patient's median cubital vein and send it to a clinical laboratory for a complete metabolic panel analysis. ${ }^{2,3}$ The time between depositing a sample and receiving results may be several hours, or approximately one hour in emergency cases. To eliminate the latency caused by hospital lab delay, POC devices such as Abbott I-STAT can perform on-site assays, including $\mathrm{Ca}^{2+}$, providing results within a few minutes. However, the frequency of assay is still dependent upon typically infrequent, professional blood draws. Though laboratory assays of $\mathrm{Ca}^{2+}$ are precise and accurate, the measurements are intermittent as compared to physiological $\mathrm{Ca}^{2+}$ dynamics. For example, in clinical cases, such as rapid blood transfusion during liver transplantations, $\mathrm{Ca}^{2+}$ concentrations can exhibit rapid transients at very low concentrations (e.g., drops by $0.1 \mathrm{mM} \mathrm{Ca}^{2+}$ in $5 \mathrm{~min}$ ), underlying the need for a continuous $\mathrm{Ca}^{2+}$ sensor. ${ }^{2,3}$

Advances in protein engineering have yielded new classes of binding macromolecules that display exquisite ligand binding specificity and yield quantifiable signals upon such ligand or target binding. ${ }^{4,5}$ For example, Maeshime, et al. developed a Förster Resonance Energy Transfer (FRET)-based molecular $\mathrm{Mg}^{2+}$ sensor to monitor $\mathrm{Mg}^{2+}$ dynamics during the cell cycle. This sensor comprises the structure-switching Escherichia coli (E. coli) $\mathrm{Mg}^{2+}$ transporter CorA (CorA-CD) positioned between the fluorescent proteins (FPs) enhanced 
cyan fluorescent protein (eCFP) and Venus (a variant of yellow fluorescent protein, YFP). ${ }^{6}$ Furthermore, a genetically encoded calcium indicator, termed Cameleon, has been reported; this sensor joins structure-switching calmodulin $(\mathrm{CaM})$ and CaM-binding peptides of Myosin Light-Chain Kinase positioned between eCFP and eYFP to monitor intracellular calcium. ${ }^{7}$ These FRET sensors demonstrate the specificity and sensitivity of genetically encoded protein biosensors.

Here, the calcium FRET sensor Twitch-2B is considered for use in a continuous $\mathrm{Ca}^{2+}$ monitor. Twitch-2B was developed by Thestrup et al. for intracellular monitoring of $\mathrm{Ca}^{2+}$ transients during T-lymphocyte activation and action potential propagation in mouse cortical neurons. ${ }^{8}$ Twitch-2B is derived from toadfish Opsanus tau Troponin C (TnC), a muscular actin-associated protein that undergoes structure-switching upon $\mathrm{Ca}^{2+}$ binding. Twitch-2B comprises a modified $\mathrm{TnC}$ (equilibrium dissociation constant for $\mathrm{Ca}^{2+}, K_{\mathrm{D}}=200 \mathrm{nM}$ ) space with linkers, each fused at their free ends to the FPs mCerulean3 (cyan FP variant) and cpVenus $^{\text {cd }}$ (yellow FP variant), at the $\mathrm{N}$ - and C-termini, respectively. ${ }^{8}$ Twitch-2B was determined to be a candidate sensing molecule for a continuous physiological $\mathrm{Ca}^{2+}$ probe because of its reversible binding kinetics, stability in vivo, and sensitivity to varying $\mathrm{Ca}^{2+}$ concentrations.

A number of calcium sensing modalities have been developed to monitor calcium. Asif et al. developed an electro-chemical sensor to $\mathrm{Ca}^{2+}$ comprising functionalized biocompatible $\mathrm{ZnO}$ nanorods. In vitro testing shows a log-linear relationship between sensor voltage and $\mathrm{Ca}^{2+}$ ranging from $100 \mathrm{nM}$ to $10 \mathrm{mM} .{ }^{10}$ Shortreed et al. functionalized the distal end of an optical fiber with the calcium sensitive dye Calcium Green and reported a unique emission spectrum for $\mathrm{Ca}^{2+}$ concentrations ranging from $37.6 \mathrm{nM}$ to $39.8 \mu \mathrm{M} .^{11}$

These reported strategies lack a method to prevent interactions with physiological macromolecules, including antibodies, proteases, and other soluble proteins, upon device implantation. Proteins from the foreign body response (FBR) can foul the surface and adversely affect sensing for in vivo applications. ${ }^{12}$ In consideration of an implantable $\mathrm{Ca}^{2+}$ sensor, a new type of $\mathrm{Ca}^{2+}$ sensor is presented that combines a FRET-based sensing molecule with a new membrane to provide the requisite protection for in vivo applications.

An optical fiber device was developed and referred to here as the membrane-encapsulated optical fiber (MEOF, Figure 1). MEOF first comprises a hydrophilic polytetrafluoroethylene (PTFE) sheet impregnated with a solution of a protein FRET sensor and placed in contact with the end of an optical fiber. MEOF also includes an outer membrane composed of a sizeselective polyethylene glycol dimethacrylate (PEGDMA) 2000 hydrogel interpenetrating a second PTFE sheet. Results are presented for $\mathrm{Ca}^{2+}$-sensing MEOF wherein the FRET sensor is a new photo-resilient variant of Twitch-2B, SNAP-Twitch-2B-CLIP (STC), which replaces the readily photobleached FPs with photostable Alexa Fluor 488 and Alex Fluor 546 as the donor and acceptor fluorophore, respectively. ${ }^{13} \mathrm{This}^{2{ }^{2+}}$ probe shows a reversible response curve for concentrations ranging between $0.01 \mathrm{mM}$ to $10 \mathrm{mM}$, and is photostable over prolonged excitation scans, a necessary capability for future implantation.

The probe also operates in real-time, which is critical for a continuous $\mathrm{Ca}^{2+}$ biosensor. 


\section{EXPERIMENTAL SECTION}

Filter-Membrane Fabrication: Monomeric PEGDMA 2000 precursor (Sigma Aldrich) and Milli-Q water were mixed with a flea-sized micro stirring bar (Grainger) in a 30\%/70\% $(w / W)$ ratio in a dark room until a homogenous solution was obtained. Photoinitiator 2Hydroxy-4' -(2-hydroxyethoxy)-2-methylpropiophenone (Irgacure 2959, Sigma Aldrich) was then mixed at $1 \%(\mathrm{~W} / \mathrm{W})$ and illuminated by a UV $(365 \mathrm{~nm}), 8 \mathrm{~W}$ VWR Dual UV Transilluminator for $10 \mathrm{~min}$ to form a hydrogel. Subsequently, filter-membranes were fabricated by polymerizing the hydrogel precursor solution while in PTFE (FHLC01300, $80 \%$ porosity, $0.45 \mu \mathrm{m}$ pore size, $145 \mu \mathrm{m}$ thick, Sigma Aldrich).

Permeability Testing: Permeability of hydrogels was tested using $3 \mathrm{~mm}$ diameter disks of PEGDMA 2000. The hydrogels were first allowed to swell overnight in Phosphate Buffered Saline Solution (PBS, pH 7.4, Thermo Fischer Scientific). Swelling reaches a steady state in $5 \mathrm{~h}$ (Supporting Information, Figure S1). The swollen hydrogels were then placed in a custom-made rubber chamber (frame size: $20 \mathrm{~mm} \times 20 \mathrm{~mm}$, mat opening: $15 \mathrm{~mm} \times 15 \mathrm{~mm}$, height: $1 \mathrm{~mm}$ McMaster-Carr), and incubated in PBS solutions containing Alexa Fluor 488 labeled insulin (5.8 kDa, Supporting Information) or Precision Plus Protein Kaleidoscope Prestained Protein Standards (Bio-Rad; $10 \mathrm{kDa}$ to $250 \mathrm{kDa}$ ) for $30 \mathrm{~min} .{ }^{13}$ Confocal microscopy was performed using either a Leica Sp8 or Zeiss LSM700 inverted microscope using 488 and $633 \mathrm{~nm}$ laser lines and a 10x or 20x objective lens. Emission was collected from 520 to $700 \mathrm{~nm}$ and 650 to $700 \mathrm{~nm}$ under 488 and $633 \mathrm{~nm}$ laser line excitation, respectively. Images were acquired every $30 \mathrm{~s}$.

The permeability of the filter-membranes was tested by first creating $1 \mathrm{~mm}$ PTFE disks with a $1 \mathrm{~mm}$ biopsy punch (World Precision Instruments). The disks were then glued (Loctite 4981, Henkel) to the face of MRE-025 microrenathane tubing (ID: $0.30 \mathrm{~mm}$, OD: $0.63 \mathrm{~mm}$, Braintree Scientific) and the hydrogel precursor solution was polymerized within the pores of the PTFE. A bare optical fiber (FG200LEA, 0.22 NA, $200 \mu \mathrm{m}$ core, $220 \mu \mathrm{m}$ cladding, Thor Labs) was guided down the tubing and placed in contact with the membrane. Loctite 4981 glue was used to seal the backend of the silica optical fiber to the microrenathane tubing. The distal end of each optical fiber terminated in an SMA thread and was coupled to a custom benchtop spectrometer apparatus (Figure S2). A set of membrane-fiber units were fabricated for each test solution described below. After incubation in PBS, the tip of each optical fiber construct was immersed in a solution containing fluorescein (FITC, 389.4 Da, Sigma Aldrich), green fluorescent protein (GFP, $26.9 \mathrm{kDa}$ ), Alexa Fluor 488 - labeled insulin $(5.8 \mathrm{kDa})$ or fluorescein isothiocyanate-dextran (3-5 kDa or $150 \mathrm{kDa}$, Sigma Aldrich). ${ }^{14,15}$

MEOF probes were fabricated as illustrated in Figure 2. Microrenathane tubing was cut into $5 \mathrm{~mm}$ segments (Figure $2 \mathrm{~A}$ ), and the glue was then applied to the bottom annulus of the tubing (Figure 2A) to adhere the tubing to a PTFE sheet (Figure 2B). A $1 \mathrm{~mm}$ biopsy punch was slipped over the tubing to cut the PTFE sheet into a circle of $1 \mathrm{~mm}$ diameter. (Figure 2C). Next, the hydrogel precursor solution was pipetted on a glass slide and the PTFEcapped tubing was pressed into the solution. The hydrogel precursor solution permeates throughout the PTFE due to their compatible hydrophilicity and was polymerized with a 365 
nm 8 W VWR Dual UV Transilluminator for $10 \mathrm{~min}$, producing a membrane-capped tube (Figures 2D). A second hydrophilic PTFE sheet was wetted with $2 \mu \mathrm{L}$ of FRET sensor solution $(4 \mathrm{mg} / \mathrm{mL})$ by first pipetting the FRET protein solution onto the PTFE material and then compressing this sheet between two microscope slides to form the sensor-matrix. In parallel, a silica optical fiber was incubated overnight in a $2 \%$ bovine serum albumin (BSA, Chromatopur) /water solution to block the optical fiber's surface and prevent surfaceinduced aggregation of the FRET sensor. Next, the sensor-matrix was placed onto the tip of the BSA-coated optical fiber (Figure 2E) and the assembly was pushed through the tubing until it contacted the filter-membrane (Figure 2F). Glue was used to seal the backend of the silica optical fiber to the microrenathane tubing, and the resulting MEOF was incubated in protein buffer media at $4{ }^{\circ} \mathrm{C}$ for at least $5 \mathrm{~h}$. The assembly quality was assessed by MEOFs encapsulating GFP to monitor for leakage. These MEOFs were incubated in 4-(2hydroxyethyl)-1-piperazineethanesulfonic acid (HEPES) buffer for $5 \mathrm{~h}$ (Figure S3), and the solution was tested for leaking GFP using a fluorescent plate reader (Spark, TECAN). No signal intensity was observed, confirming encapsulation of the protein within the sensormatrix.

FRET Calcium Sensing: Each spectral measurement was acquired in triplicate with exposure times of $100 \mathrm{~ms}$ for the Twitch-2B sensor or $2 \mathrm{~s}$ for the STC sensor. Back-ground (dark signal)-subtracted spectra were processed in MATLAB. Custom MATLAB code was used to process the digitized signals and calculate the FRET ratiometric signal, which here is defined as the peak acceptor intensity signal divided by the peak donor intensity signal $\left(\mathrm{I}_{\text {acceptor }} / \mathrm{I}_{\text {donor }}\right)$, a metric commonly used to quantify FRET efficiency. ${ }^{16}$

Calcium solutions $\left(\mathrm{CaCl}_{2} * 2 \mathrm{H}_{2} \mathrm{O}\right.$, Sigma Aldrich) at the indicated concentration were placed in microcentrifuge tubes capped with parafilm to prevent evaporation. MEOF probes were tested by dipping the devices into these calcium solutions. GraphPad Prism was used for to fit data points onto nonlinear regression models and for statistical analysis.

\section{RESULTS AND DISCUSSION Characterization of the Filter-Membrane}

A well-known event, the FBR activates upon device implantation. ${ }^{12}$ Of particular importance to the MEOF $\mathrm{Ca}^{2+}$ probe, the FBR recruits immune cells that secrete proteases, which could cleave the Twitch-2B and render the device inoperable. Thus, the device must exclude protease access to the molecular sensor.

Here, PEG hydrogels are formulated to size-exclude proteases secreted by immune cells. Such proteases are considerably smaller than immunoglobulins ( $150 \mathrm{kDa})$, and much larger than calcium ions. ${ }^{17}$ The smallest of these known proteases is Chymase, which has a MW of approximately $30 \mathrm{kDa} .{ }^{18}$ PEG-derived hydrogels were selected for protein exclusion due to the tunability of their mesh size, swelling, and tensile strength. ${ }^{19,20}$ Additionally, PEG is considered to be generally nonfouling and biocompatible. ${ }^{21}$ Screening of various PEG formulations and derivates lead to the selection of PEGDMA 2000 hydrogels, formulated as described in the Experimental Section, and were shown to exclude proteins as small as 10 $\mathrm{kDa}$, but permit transport of insulin $(5.8 \mathrm{kDa})$. Fluorescence signals from the fluorescently 
labeled insulin at the hydrogel/fluid interface show very rapid kinetics (Figure 3A,3C); in comparison, the $10 \mathrm{kDa}$ and larger proteins show no penetration of the hydrogel as measured by fluorescence (Figure 3B, 3C).

The PEGDMA 2000 hydrogels are very soft when hydrated, however and too fragile to place on the tip of a probe for implantation. Thus, a protective PTFE layer was devised. The hydrogel precursor solution was polymerized within the non-solid phase of commercially available hydrophilic PTFE sheets. Scanning electron microscopy (FEI Magellan 400 XHR, Electron Microscopy Solutions) after iridium sputter coating (10nm, EMS 150T, Electron Microscopy Solutions) reveal the natural porosity of PTFE sheets (Figure 4A) and their impregnation by the PEGDMA 2000 hydrogel (Figure 4B). This composite, termed the filtermembrane, combines the size-exclusion properties of the PEGDMA 2000 hydrogel with the durability of PTFE sheets, and offers a robust composite material for the tip of the $\mathrm{Ca}^{2+}$ sensing device.

Filter-membranes were tested to ensure they retain the size selectivity of the hydrogel alone. For each test, a filter-membrane was coupled to the end of an optical fiber as described in the Experimental Section. Figure 5A reports that FITC, 3-5 kDa fluorescein isothiocyanatedextran and Alexa Fluor 488-labeled insulin can diffuse through the filter-membrane, while large macromolecules GFP and $150 \mathrm{kDa}$ fluorescein isothiocyanate-dextran cannot. Figures S4A and S4B display the timedependent emission spectra of Alexa Fluor 488 - labeled insulin and GFP. These results show the filter-membrane retains the size-exclusion properties of the hydrogel.

\section{Twitch-2B Ca ${ }^{2+}$ Probe}

Calcium sensing membrane-encapsulated optical fiber (MEOF) biosensors were fabricated as detailed in the Experimental Section, where the FRET molecular sensor was Twitch-2B. Important to the FRET sensor, the sensor-matrix allows Twitch-2B to remain in solution, preserving Twitch-2B structure-switching upon $\mathrm{Ca}^{2+}$ binding and unbinding. The resulting MEOF probe has the following key properties. 1) enabling the passage of small target analytes (e.g., ions and small peptides) yet exclusion of larger proteins (such as serine proteases), 2) allowing FRET sensors to undergo conformational changes upon binding and releasing target analytes, and 3) guiding excitation light to the sensor-matrix and fluorescently emitted light to the spectrometer.

\section{In Vitro Testing of MEOF $\mathrm{Ca}^{2+}$ Probes}

To determine the efficacy of the Twitch-2B MEOF $\mathrm{Ca}^{2+}$ probe, probes were incubated in test buffer (25 mM 3-(N-morpholino) propanesulfonic acid (MOPS), $100 \mathrm{mM} \mathrm{KCl}, \mathrm{pH}$ 7.6) supplemented with increasing concentrations of $\mathrm{Ca}^{2+}$. For each measurement, $0.7 \mu \mathrm{W}$ of 405 $\mathrm{nm}$ laser light was used to excite the protein sensor for $100 \mathrm{~ms}$. Results show the FRET ratio (Iacceptor / Idonor) being sensitive to increasing $\mathrm{Ca}^{2+}$ concentration from 0 to $14 \mathrm{mM}$, above which the sensor response saturates (Figure 6A). Importantly, the MEOF sensor responds in the physiological concentration range of $\mathrm{Ca}^{2+}$; normal non-protein bound $\mathrm{Ca}^{2+}$ concentration in human blood plasma ranges from 1.1 to $1.3 \mathrm{mM}$ with pathological values ranging from $0.33 \mathrm{mM}$ (hypocalcemia) to $2.5 \mathrm{mM}$ (hypercalcemia). ${ }^{11,22,23}$ The probe- 
response curve was fit to a Hill equation, which determined the $K_{\mathrm{D}}$ and Hill constant to be $2.3 \mathrm{mM}$ and 0.78 , respectively $\left(\mathrm{R}^{2}\right.$ (Coefficient of Determination) $=0.99$, Sy.x (Standard Error of the Estimate) $=0.07$ ) consistent with binding affinity in a useful range. These results demonstrate that the intracellular FRET sensor Twitch-2B can be adapted to function in a hand-held optical device.

However, the Twitch-2B accepter fluorophore, cpVenus $^{\text {cd }}$ (a YFP derivative) is susceptible to photobleaching, particularly as compared to the donor fluorophore mCerulean3 (a CFP derivative) ${ }^{24}$ The photostability of the Twitch-2B MEOF device was therefore investigated by repeated exposure to $405 \mathrm{~nm}$ while in calcium-free test buffer. The FRET ratio was measured after each exposure and showed significant photobleaching over time (Figure 6B), following an exponential decay in FRET ratio $\left(\mathrm{R}^{2}=0.99\right.$, Sy. $\left.\mathrm{x}=0.04\right)$, as expected for exponential photobleaching. ${ }^{25,26}$ Further, it has been shown that the CFP-YFP FRET pair may suffer from phototoxicity when excited with violet wavelengths, resulting in inactivation of the FRET pair. ${ }^{24}$ To account for possible effects specific to the MEOF, photobleaching experiments were conducted using solutions of Twitch-2B. Twitch-2B solutions were exposed to $45 \mathrm{~mW}, 405 \mathrm{~nm}$ laser light for three min; a non-illuminated solution served as a negative control. Solutions were analyzed with the spectroscopic fluorescent plate reader under three conditions: donor excitation in test buffer, acceptor excitation in test buffer, and donor excitation in test buffer supplemented with $\mathrm{CaCl}_{2}$. Spectroscopic data (Figure S5) confirm photobleaching and consequential loss of sensitivity to $\mathrm{Ca}^{2+}$.

The Development of a Photostable Twitch-2B FRET Construct To overcome cpVenus ${ }^{\mathrm{cd}}$ photobleaching during MEOF measurements, photostable fluorescent molecules were sought to replace the mCerulean3-cpVenus ${ }^{\mathrm{cd}}$ FRET pair. Small molecule Alexa Fluor dyes are highly suitable candidates for the MEOF FRET sensor as they provide greater photostability and brightness compared to genetically encoded fluorescent proteins and other fluorescent dyes like $\mathrm{Cy} 3$ and fluorescein. ${ }^{27,28}$ To conjugate Alexa Fluor dyes, geneticallyencoded SNAP- and CLIP-tags were integrated into Twitch-2B. SNAP and CLIP-tags, both derived from the human $\mathrm{O}^{6}$-alkylguanine transferase; catalyze the covalent attachment of an $\mathrm{O}^{6}$-benzylguanine $\left(\mathrm{O}^{6}-\mathrm{BG}\right)$ and $\mathrm{O}^{6}$-benzylcytosine $\left(\mathrm{O}^{6}-\mathrm{BC}\right)$, respectively. ${ }^{33}$

The Twitch-2B sensor was reengineered with SNAP and CLIP tags flanking its N- and C termini, resulting in, SNAP-Twitch-2B-CLIP, termed STC. The plasmid encoding STC and plasmid map are shown in Figure S6 and S7. The new construct was expressed at high yields and purified using affinity and size exclusion chromatography (Figure S8A). Commercially available $\mathrm{O}^{6}$-BG Alexa Fluor 488 and $\mathrm{O}^{6}$-BC-Alexa Fluor 546-BC (New England Biolabs) were covalently attached onto the SNAP and CLIP tags of STC (Figure S8B, S8C), and the FRET construct retained its dose-dependent response to $\mathrm{Ca}^{2+}$ in a 96-well fluorescent plate assays (Figure 7). The STC construct was, henceforth, used in further investigations of the MEOF probes.

\section{Characterization of MEOF Probes with the STC Construct}

Here, probe photostability was assessed using a $450 \mathrm{~nm}$ laser light to excite the donor fluorophore Alexa Fluor 488. Each MEOF was incubated in Reference Buffer (RB, $50 \mathrm{mM}$ 
HEPES, $50 \mathrm{mM} \mathrm{NaCl}, 10 \%$ glycerol, $10 \mathrm{mM} \beta$-mercaptoethanol ( $\beta \mathrm{ME}), \mathrm{pH}$ 7.6) and exposed to $0.71 \mathrm{~mW}$ laser for $2 \mathrm{~s}$ per reading. Laser light energy per measurement is 20E3 times greater for STC as compared to Twitch-2B. No significant FRET ratio change was observed during the experiment (Figure 8A, Relative Standard Deviation, RSD $=0.57 \%$ ). Thus, integration of the new donor and acceptor fluorophores provide sufficient photostability for continuous $\mathrm{Ca}^{2+}$ monitoring.

The sensor rise time was assessed by first incubating MEOF probes in $\mathrm{RB}$ and then in $\mathrm{RB}$ supplemented with $1.25 \mathrm{mM} \mathrm{CaCl}_{2}$. The FRET ratio was recorded every $3 \mathrm{~min}$ for $30 \mathrm{~min}$ after media exchange. The data follow an exponential plateau function $\left(\mathrm{R}^{2}=0.98\right.$, Sy.x $=$ 0.004) with a rise time of approximately $6 \mathrm{~min}$, without detectable photobleaching within the plateau ( $\mathrm{RSD}=0.47 \%$ ) (Figure $8 \mathrm{~B}$ ). The $6 \mathrm{~min}$ rise time is similar to that of commercial analytical devices, for example, continuous glucose monitors, known to be effective in guiding treatment of conditions having rapid and slow transients such as seen in type 1 diabetes. ${ }^{35}$

Next, MEOF probes were incubated in RB solutions having $\mathrm{Ca}^{2+}$ concentration ranging from 0 to $20 \mathrm{mM}$. The data shows sensitivity to $\mathrm{Ca}^{2+}$ across the measured range $(0.01 \mathrm{mM}$ to $10 \mathrm{mM}$ ), and a functional form consistent with the Hill equation (Figure $8 \mathrm{C} ; \mathrm{R}^{2}=0.99$, Sy.x $=0.01$ ) having a Hill constant and $K_{\mathrm{D}}$ values of 0.4 and $0.1 \mathrm{mM}$, respectively. As indicated by the green region in Figure $8 \mathrm{C}$, the MEOF is sensitive across the physiological range of ionized $\mathrm{Ca}^{2+}$ concentration in the blood, and extends the dynamic range of the $\mathrm{Ca}^{2+}$ sensing modalities previously mentioned. ${ }^{11-13}$ This extended sensitivity range correlates with the Hill constant being less than one, affording a stretched 'linear region' of sensitivity. 36

To test for sensor reversibility, MEOF probes were serially placed in RB solutions with or without $1 \mathrm{mM} \mathrm{CaCl}_{2}$ (Figure 8D;). A one-way ANOVA was conducted to compare effects of $\mathrm{Ca}^{2+}$ on FRET ratio. There was a significant effect of $\mathrm{Ca}^{2+}$ across all groups $(\mathrm{P}<0.0001)$. The Tukey post-hoc comparison with adjusted $\mathrm{P}$ values shows no significant differences between the three $\mathrm{RB}$ solution groups or the two $\mathrm{RB}+1 \mathrm{mM} \mathrm{CaCl}_{2}$ groups ( $\mathrm{p} \geq 0.99$ for each comparison), but significant differences between each pairing of $\mathrm{RB}$ or $\mathrm{RB}+1 \mathrm{mM}$ $\mathrm{CaCl}_{2}$ groups ( $\mathrm{p}<0.0001$ for each comparison). Notably, sensor dynamics are considerably slower when comparing $\mathrm{Ca}^{2+}$ unbinding (Figure S9) to binding (Figure 8B). Although the cytoplasmic Twitch-2B has previously demonstrated rapid unbinding kinetics in cellulo, cells contain orders of magnitude lower calcium concentration as compared to the blood and contain unique pumps and transporters that rapidly reduce cytoplasmic $\mathrm{Ca}^{2+}$ concentration.

${ }^{37}$ And so, it is unsurprising that MEOF fall-times are relatively long given the passive diffusion of $\mathrm{Ca}^{2+}$ ions at concentrations mimicking the blood.

\section{Protection from Proteolytic Enzymes}

To model immune system proteolytic enzymes secretion during the FBR, the STC MEOF was incubated with the endopeptidase serine protease Proteinase K (28.9 kDa, New England Biolabs). ${ }^{38}$ The solution comprises $692 \mu \mathrm{M}$ proteinase $\mathrm{K}$ in a solution of $20 \mathrm{mM}$ Tris- $\mathrm{HCl}, 1$ $\mathrm{mM} \mathrm{CaCl}_{2}$ and $50 \%$ glycerol by volume. Emission spectra confirm that proteinase $\mathrm{K}$ in the $\mathrm{Ca}^{2+}$ solution rapidly cleaves the STC and results in a $26 \%$ loss in acceptor fluorescence 
(Figure 9A). Conversely, uncleaved STC should show an increase in acceptor fluorescence over time due to FRET. This increase is observed for the MEOF incubated in the proteinase $\mathrm{K}$ solution for $30 \mathrm{~min}$, demonstrating that the filter-membrane successfully excludes the proteinase K (Figure 9B). These findings highlight the need for and the key role of the sizeexcluding filter-membrane to circumvent the FBR.

\section{CONCLUSION}

This effort has produced an optical fiber-based probe, MEOF, designed for prolonged measurements of $\mathrm{Ca}^{2+}$ concentrations in vivo. Such capabilities result from (1) encapsulating protein FRET sensors within the pores of a mechanically robust PTFE sheet, such that FRET sensors are free to undergo conformation changes, (2) excluding host proteases by a hybrid PTFEPEGDMA membrane, and (3) elimination of deleterious photobleaching of FPs in the Twitch-2B FRET sensor by installing small molecules for the donor and acceptor FPs, respectively. This approach is generalizable to the larger class of protein FRET sensors ( e.g. ATP and $\mathrm{Zn}^{2+}$ ). ${ }^{39,40}$ Further, the molecular weight cut off properties of the hybrid filter-membrane can be tuned for other applications or FRET sensors by new hydrogel formulation comprising PEG derivatives, or other commonly used hydrogels such as alginate and hyaluronic acid. In summary, the MEOF probe can be easily adopted to include new FRET sensors to generate a new class of analytical probes.

\section{Supplementary Material}

Refer to Web version on PubMed Central for supplementary material.

\section{ACKNOWLEDGMENT}

This work was supported by the NIH National Institute of Environmental Health Sciences (NIEHS) CounterACT Program Grant Number U54NSES027698, Juvenile Diabetes Research Foundation (2-SRA-2017-330-Q-R), Helmsley Charitable Trust (2018PG-T1D008), National Science Foundation IGERT BEST Training Program (144901), and the Cardiovascular Applied Research and Entrepreneurship Fellowship through the Edwards Lifesciences Center for Advanced Cardiovascular Technology's NIH/NHLBI T32 Training Program (T32HL116270).

\section{REFERENCES:}

(1). Seshadri DR; Li RT; Voos JE; Rowbottom JR; Alfes CM; Zorman CA; Drummond CK Wearable Sensors for Monitoring the Physiological and Biochemical Profile of the Athlete. npj Digit. Med 2019, 2 (1). 10.1038/s41746-019-0150-9.

(2). Díaz J; Acosta F; Parrilla P; Sansano T; Contreras RF; Bueno FS; Martínez P Correlation among Ionized Calcium, Citrate, and Total Calcium Levels during Hepatic Transplantation. Clin. Biochem 1995, 28 (3), 315-317. 10.1016/0009-9120(94)00094-C. [PubMed: 7554253]

(3). Chung HS; Cho SJ; Park CS Effects of Liver Function on Ionized Hypocalcaemia Following Rapid Blood Transfusion. J. Int. Med. Res 2012, 40 (2), 572-582. 10.1177/147323001204000219. [PubMed: 22613418]

(4). Chockalingam K; Zhao H Directed Evolution of Specific Receptor-Ligand Pairs for Use in the Creation of Gene Switches. In AIChE Annual Meeting, Conference Proceedings; 2005; p 9272 10.1073/pnas.0409206102.

(5). Di Roberto RB; Chang B; Peisajovich SG The Directed Evolution of Ligand Specificity in a GPCR and the Unequal Contributions of Efficacy and Affinity. Sci. Rep 2017, 7 (1). 10.1038/ s41598-017-16332-2. 
(6). Maeshima K; Matsuda T; Shindo Y; Imamura H; Tamura S; Imai R; Kawakami S; Nagashima R; Soga T; Noji H; et al. A Transient Rise in Free Mg2+ Ions Released from ATP-Mg Hydrolysis Contributes to Mitotic Chromosome Condensation. Curr. Biol 2018, 28 (3), 444-451.e6. 10.1016/j.cub.2017.12.035. [PubMed: 29358072]

(7). Lindenburg L; Merkx M Engineering Genetically Encoded FRET Sensors Sensors (Switzerland). MDPI AG 7 2, 2014, pp 11691-11713. 10.3390/s140711691.

(8). Thestrup T; Litzlbauer J; Bartholomäus I; Mues M; Russo L; Dana H; Kovalchuk Y; Liang Y; Kalamakis G; Laukat Y; et al. Optimized Ratiometric Calcium Sensors for Functional in Vivo Imaging of Neurons and t Lymphocytes. Artic. Nat. methods |2014, 11 (2), 175 10.1038/ nmeth. 2773.

(9). Hall WP; Anker JN; Lin Y; Modica J; Mrksich M; Van Duyne RP A Calcium-Modulated Plasmonic Switch. 10.1021/ja7109037.

(10). Asif MH; Fulati A; Nur O; Willander M; Brännmark C; Strälfors P; Börjesson SI; Elinder F Functionalized Zinc Oxide Nanorod with Ionophore-Membrane Coating as an Intracellular Ca2+ Selective Sensor. Appl. Phys. Lett 2009, 95 (2). 10.1063/1.3176441.

(11). Shortreed M; Kopelman R; Kuhn M; Hoyland B Fluorescent Fiber-Optic Calcium Sensor for Physiological Measurements. Anal. Chem 1996, 68 (8), 1414-1418. 10.1021/ac950944k. [PubMed: 8651501]

(12). Kastellorizios M; Tipnis N; Burgess DJ Foreign Body Reaction to Subcutaneous Implants. Adv. Exp. Med. Biol 2015, 865, 93-108. 10.1007/978-3-319-18603-0_6. [PubMed: 26306445]

(13). Fu Z; Gilbert RE,; Liu D Regulation of Insulin Synthesis and Secretion and Pancreatic Beta-Cell Dysfunction in Diabetes. Curr. Diabetes Rev 2012, 9 (1), 25-53. 10.2174/15733998130104.

(14). Hink MA; Griep RA; Borst JW; Van Hoek A; Eppink MHM; Schots A; Visser AJWG Structural Dynamics of Green Fluorescent Protein Alone and Fused with a Single Chain Fv Protein. J. Biol. Chem 2000, 275 (23), 17556-17560. 10.1074/jbc.M001348200. [PubMed: 10748019]

(15). Woting A; Blaut M Small Intestinal Permeability and Gut-Transit Time Determined with Low and High Molecular Weight Fluorescein Isothiocyanate-Dextrans in C3H Mice. Nutrients 2018, 10 (6). 10.3390/nu10060685.

(16). Algar WR; Hildebrandt N; Vogel SS; Medintz IL FRET as a Biomolecular Research Tool Understanding Its Potential While Avoiding Pitfalls. Nat. Methods 2019, 16 (9), 815-829. 10.1038/s41592-019-0530-8. [PubMed: 31471616]

(17). Lipman NS; Jackson LR; Trudel LJ; Weis-Garcia F Monoclonal Versus Polyclonal Antibodies: Distinguishing Characteristics, Applications, and Information Resources. ILAR J. 2005, 46 (3), 258-268. 10.1093/ilar.46.3.258. [PubMed: 15953833]

(18). Dell'italia LJ; Collawn JF; Ferrario CM Multifunctional Role of Chymase in Acute and Chronic Tissue Injury and Remodeling Circulation Research. Lippincott Williams and Wilkins 1 1, 2018, pp 319-336. 10.1161/CIRCRESAHA.117.310978.

(19). Lin CC; Anseth KS PEG Hydrogels for the Controlled Release of Biomolecules in Regenerative Medicine. Pharmaceutical Research. 3 2009, pp 631-643. 10.1007/s11095-008-9801-2. [PubMed: 19089601]

(20). Lanasa SM; Hoffecker IT; Bryant SJ Presence of Pores and Hydrogel Composition Influence Tensile Properties of Scaffolds Fabricated from Well-Defined Sphere Templates. J. Biomed. Mater. Res. - Part B Appl. Biomater 2011, 96 B (2), 294-302. 10.1002/jbm.b.31765. [PubMed: 21210509]

(21). Jang HJ; Shin CY; Kim KB Safety Evaluation of Polyethylene Glycol (PEG) Compounds for Cosmetic Use. Toxicol. Res 2015, 31 (2), 105-136. 10.5487/TR.2015.31.2.105. [PubMed: 26191379]

(22). Renaghan AD; Rosner MH Hypercalcemia: Etiology and Management. Nephrol. Dial. Transplant 2018, 33 (4), 549-551. 10.1093/ndt/gfy054.

(23). Anastasopoulos D; Kefaliakos A; Michalopoulos A Is Plasma Calcium Concentration Implicated in the Development of Critical Illness Polyneuropathy and Myopathy? Crit. Care 2011, 15 (5), R247 10.1186/cc10505. [PubMed: 22018206]

(24). Bajar BT; Wang ES; Zhang S; Lin MZ; Chu J A Guide to Fluorescent Protein FRET Pairs Sensors (Switzerland). MDPI AG 9 14, 2016 10.3390/s16091488. 
(25). Van Munster EB; Kremers GJ; Adjobo-Hermans MJW; Gadella TWJ Fluorescence Resonance Energy Transfer (FRET) Measurement by Gradual Acceptor Photobleaching. J. Microsc 2005, 218 (3), 253-262. 10.1111/j.1365-2818.2005.01483.x. [PubMed: 15958019]

(26). Derieppe M; Bos C; De Greef M; Moonen C; Denis De Senneville B Correction for Photobleaching in Dynamic Fluorescence Microscopy: Application in the Assessment of Pharmacokinetic Parameters in Ultrasound-Mediated Drug Delivery. Phys. Med. Biol 2015, 61 (2), 588-600. 10.1088/0031-9155/61/2/588. [PubMed: 26689685]

(27). Panchuk-Voloshina N; Haugland RP; Bishop-Stewart J; Bhalgat MK; Millard PJ; Mao F; Leung WY; Haugland RP Alexa Dyes, a Series of New Fluorescent Dyes That Yield Exceptionally Bright, Photostable Conjugates. J. Histochem. Cytochem 1999, 47 (9), 1179-1188. 10.1177/002215549904700910. [PubMed: 10449539]

(28). Regoes A; Hehl AB SNAP-TagTM Mediated Live Cell Labeling as an Alternative to GFP in Anaerobic Organisms. Biotechniques 2005, 39 (6), 809-812. 10.2144/000112054. [PubMed: 16382896]

(29). Gahl RF; Tekle E; Tjandra N Single Color FRET Based Measurements of Conformational Changes of Proteins Resulting from Translocation inside Cells. Methods 2014, 66 (2), 180-187. 10.1016/j.ymeth.2013.07.011. [PubMed: 23872323]

(30). Ishitsuka Y; Azadfar N; Kobitski AY; Nienhaus K; Johnsson N; Nienhaus GU Evaluation of Genetically Encoded Chemical Tags as Orthogonal Fluorophore Labeling Tools for SingleMolecule Fret Applications. J. Phys. Chem. B 2015, 119 (22), 6611-6619. 10.1021/ acs.jpcb.5b03584. [PubMed: 25978145]

(31). Stephanopoulos N; Francis MB Choosing an Effective Protein Bioconjugation Strategy Nature Chemical Biology. Nature Publishing Group 2011, pp 876-884. 10.1038/nchembio.720.

(32). Nanda JS; Lorsch JR Labeling of a Protein with Fluorophores Using Maleimide Derivitization In Methods in Enzymology; Academic Press Inc., 2014; Vol. 536, pp 79-86. 10.1016/ B978-0-12-420070-8.00007-6. [PubMed: 24423268]

(33). Gautier A; Juillerat A; Heinis C; Corrêa IR; Kindermann M; Beaufils F; Johnsson K An Engineered Protein Tag for Multiprotein Labeling in Living Cells. Chem. Biol 2008, 15 (2), 128136. 10.1016/j.chembiol.2008.01.007. [PubMed: 18291317]

(34). Sun X; Zhang A; Baker B; Sun L; Howard A; Buswell J; Maurel D; Masharina A; Johnsson K; Noren CJ; et al. Development of SNAP-Tag Fluorogenic Probes for Wash-Free Fluorescence Imaging. ChemBioChem 2011, 12 (14), 2217-2226. 10.1002/cbic.201100173. [PubMed: 21793150]

(35). Zaharieva DP; Turksoy K; McGaugh SM; Pooni R; Vienneau T; Ly T; Riddell MC Lag Time Remains with Newer Real-Time Continuous Glucose Monitoring Technology During Aerobic Exercise in Adults Living with Type 1 Diabetes. Diabetes Technol. Ther 2019, 21 (6), 313-321. 10.1089/dia.2018.0364. [PubMed: 31059282]

(36). Kurganov BI; Lobanov AV; Borisov IA; Reshetilov AN Criterion for Hill Equation Validity for Description of Biosensor Calibration Curves. Anal. Chim. Acta 2001, 427 (1), 11-19. 10.1016/ S0003-2670(00)01167-3.

(37). Bagur R; Hajnóczky G Intracellular Ca2+ Sensing: Its Role in Calcium Homeostasis and Signaling Molecular Cell. Cell Press 6 15, 2017, pp 780-788. 10.1016/j.molcel.2017.05.028.

(38). Mótyán J; Tóth F; Tőzsér J Research Applications of Proteolytic Enzymes in Molecular Biology. Biomolecules 2013, 3 (4), 923-942. 10.3390/biom3040923. [PubMed: 24970197]

(39). Sanford L; Palmer A Recent Advances in Development of Genetically Encoded Fluorescent Sensors In Methods in Enzymology; Academic Press Inc., 2017; Vol. 589, pp 1-49. 10.1016/ bs.mie.2017.01.019. [PubMed: 28336060]

(40). Vinkenborg JL; Nicolson TJ; Bellomo EA; Koay MS; Rutter GA; Merkx M Genetically Encoded FRET Sensors to Monitor Intracellular Zn2+ Homeostasis. Nat. Methods 2009, 6 (10), 737-740. 10.1038/nmeth.1368. [PubMed: 19718032] 
(A)

(B)

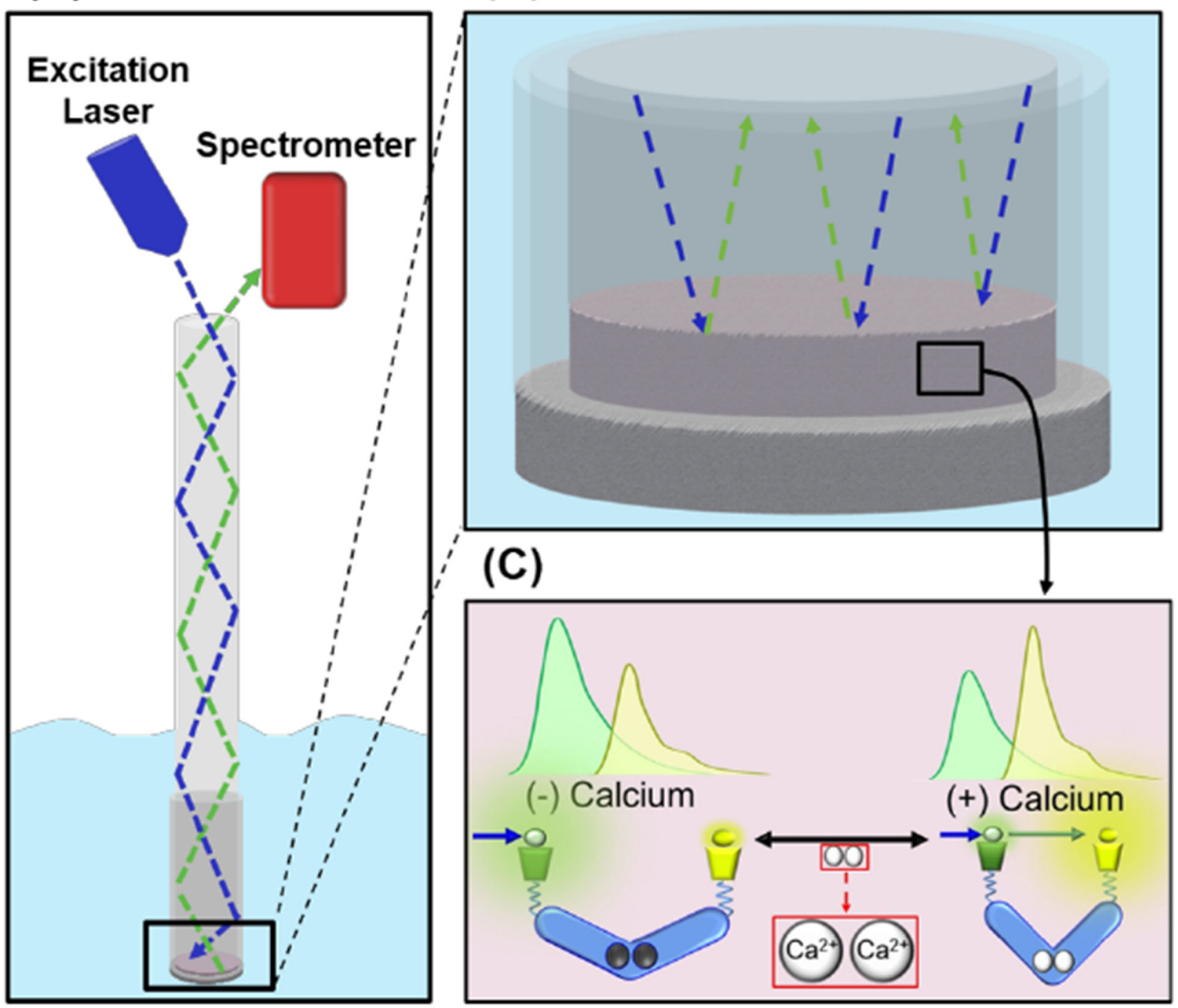

Figure 1.

Schematic of the FRET calcium ion probe. (A) Excitation light results in a FRET signal analyzed by a spectrometer. (B) A size-excluding filter-membrane and sensor-matrix encapsulate the optical fiber. (C) The FRET signal is modulated by calcium ion concentration. 
(A)

(B)

(C)

(D)

(E)

(F)

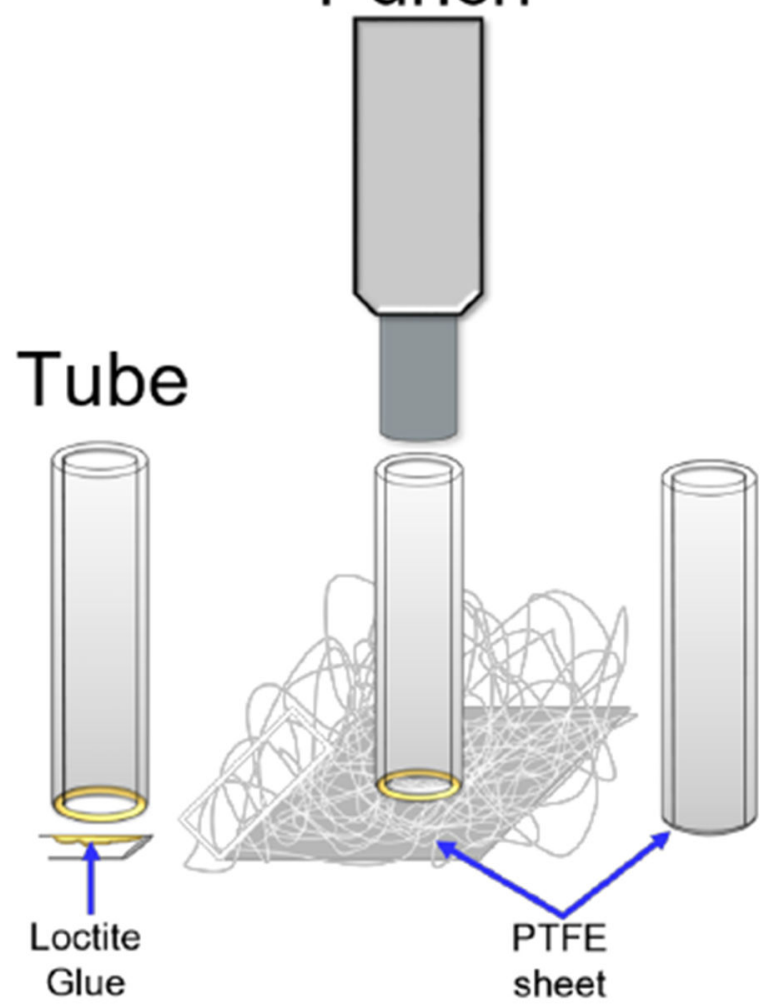

Biopsy Punch
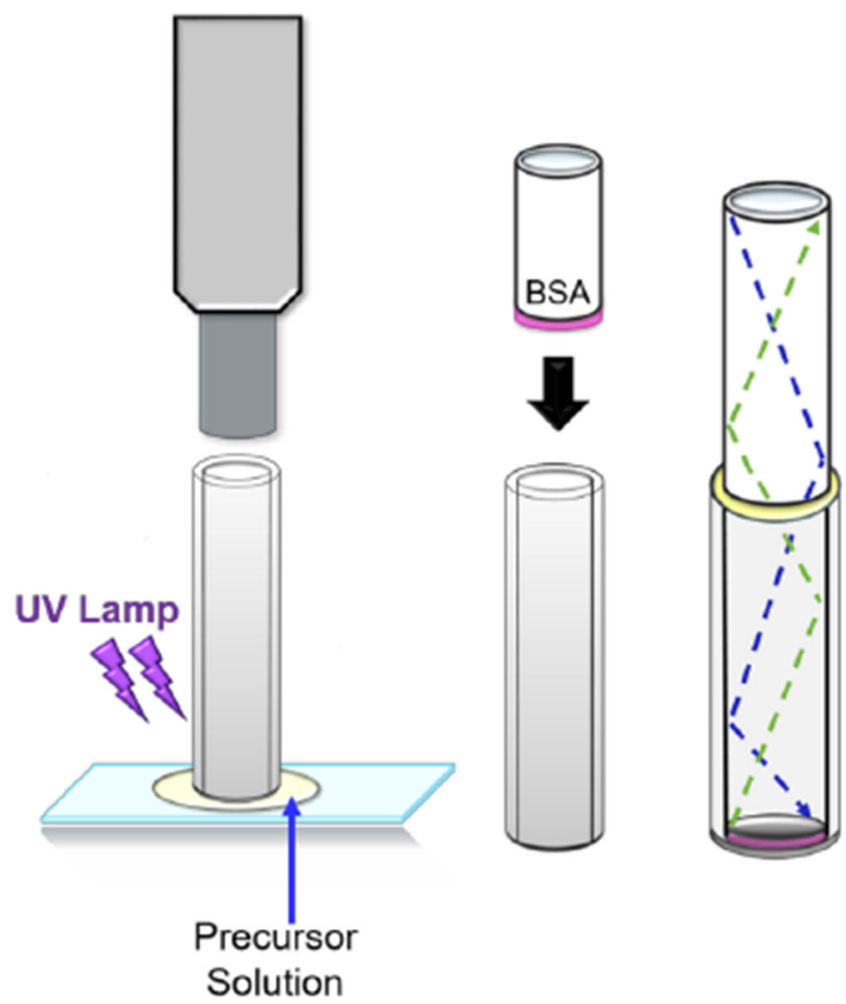

Figure 2.

Fabrication of the membrane-encapsulated optical fiber (MEOF). (A) Microrenathane tubing is cut, and Loctite 4981 glue is applied by a small needle to its tip. The tubing is placed onto a sheet of PTFE cut by biopsy punch (B) to produce a capped tube (C). PEGDMA 2000 hydrogel precursor solution is allowed to impregnate the PTFE sheet (D) such that after polymerization, a hybrid PEGDMA2000/PTFE membrane is produced. An optical fiber guides an PTFE sheet, wetted with FRET protein solution (shown in pink), to the end of the tubbing (E) and then sealed on the back end with Loctite 2981 glue (F). Fabrication of the Membrane-Encapsulated Optical Fiber (MEOF) 
(A)

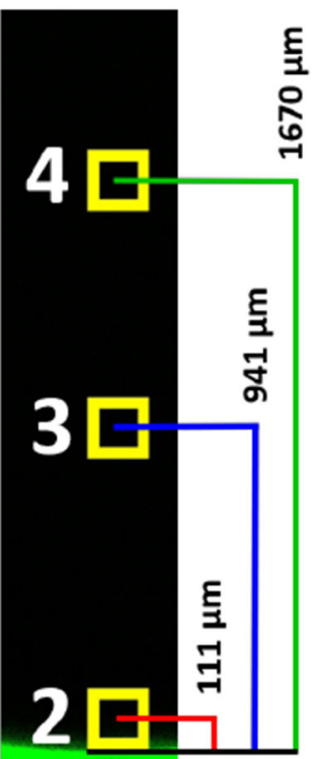

$1 \square$
(B)

(C)

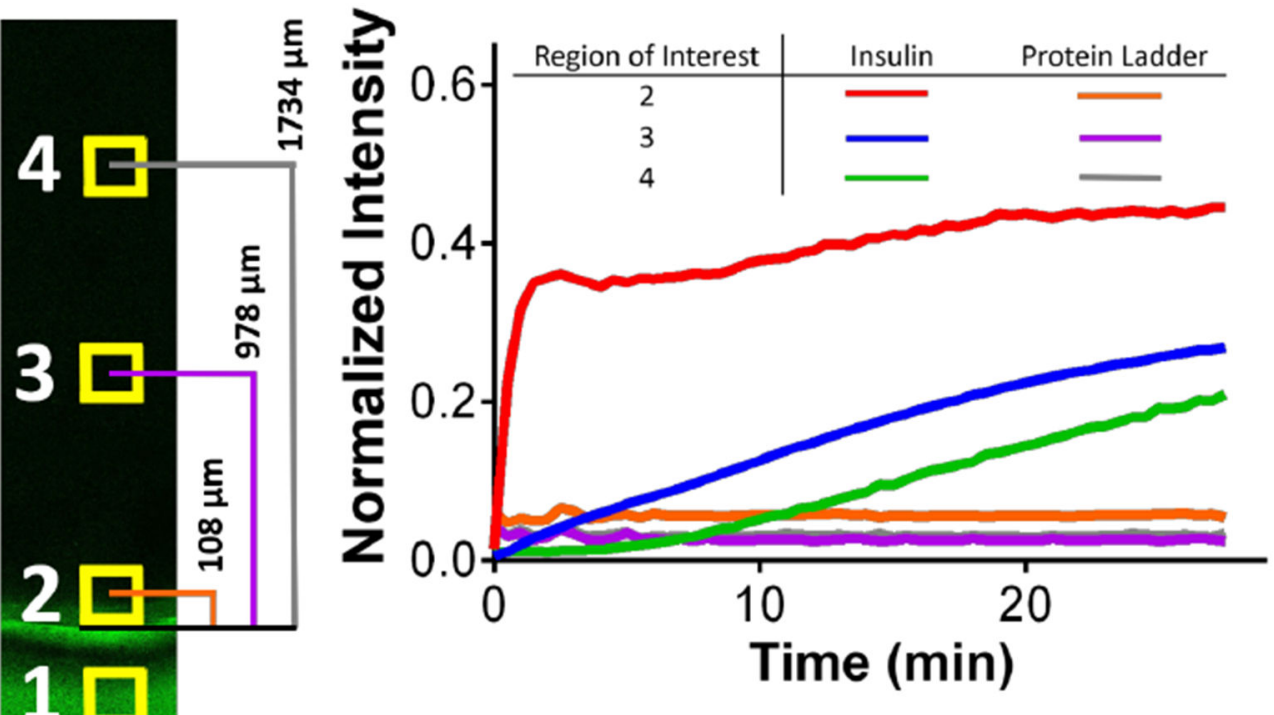

Figure 3.

Examining the permeability of the PEGDMA 2000 hydrogel. (A) Confocal micrographs of the PEGDMA 2000 hydrogel surrounded by Alexa Fluor 488-labeled insulin (20X image) or (B) a protein ladder (Bio-Rad Protein Kaleidoscope; 10X image) were captured at $\mathrm{t}=0$. (C) Intensity profiles highlight permeabilization by proteins into the indicated regions of interests (ROIs) over time with normalization for fluorescence in ROI 1. ImageJ software was used to analyze ROI intensity. 
(A)

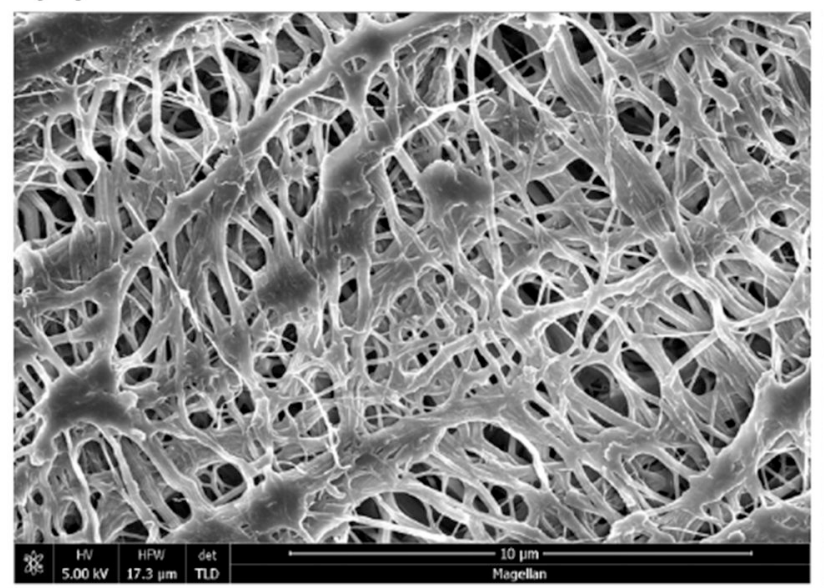

(B)

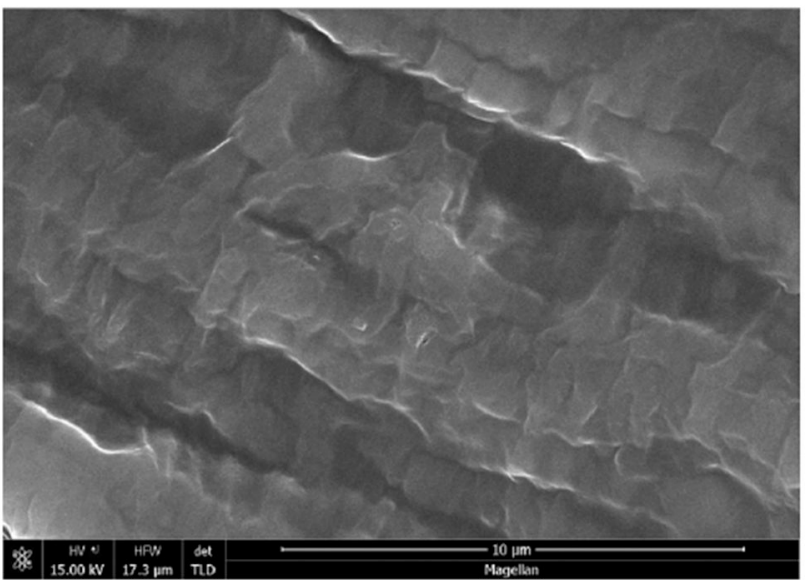

Figure 4.

SEM images of PTFE and the filter-membrane. Scale Bar $=10 \mu \mathrm{m}$. A) The PTFE sheets contain $0.45 \mu \mathrm{m}$ pores that are infiltrated with PEGDMA 2000 hydrogels (B) after UV polymerization. 
(A)

\begin{tabular}{cccccc}
\hline & Fluorescein & Dextran & Insulin & GFP & Dextran \\
\hline $\begin{array}{c}\text { Molecular } \\
\text { Weight }(\mathrm{kDa})\end{array}$ & 0.38 & $3-5$ & 5.8 & 26.9 & 150 \\
$\begin{array}{c}\text { Membrane } \\
\text { Permeable? }\end{array}$ & Yes & Yes & Yes & No & No
\end{tabular}

Figure 5.

Properties of the filter-membrane. (A) Tabulated permeability results indicate the observed penetration by fluorescently labeled analytes. 
(A)

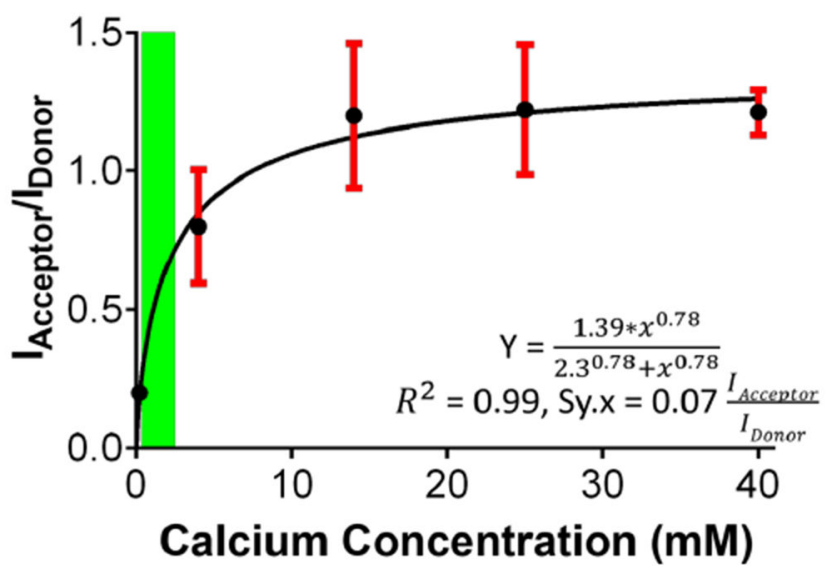

(B)

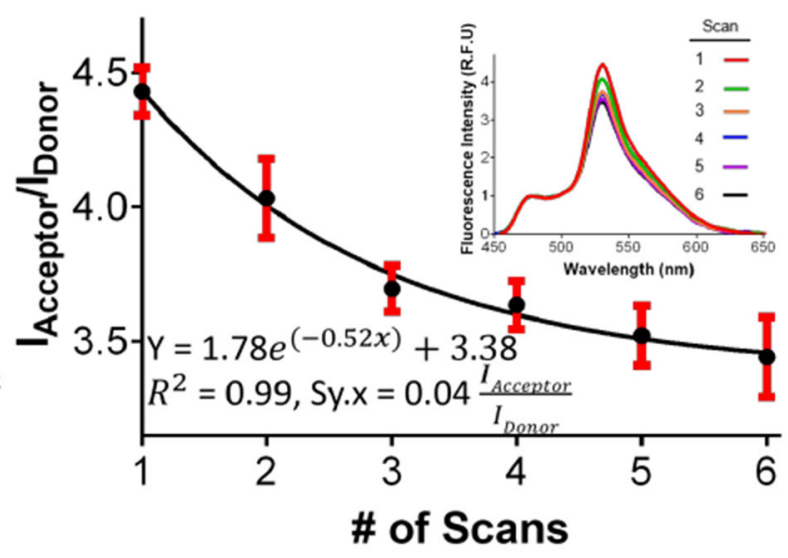

Figure 6.

Efficacy of Twitch2B to sense calcium ions. (A) The dose-dependent response of the MEOF and its data fit to a Hill equation demonstrates the MEOF's usefulness for sensing physiological concentrations of $\mathrm{Ca}^{2+}$ (green). $\mathrm{I}_{\text {acceptor }} / \mathrm{I}_{\text {donor }}$ is the emission ratio after subtracting the spectra for calcium ion-free MOPS buffer. (B) Photobleaching of mCerulean 3 and $c p$ Venus ${ }^{\mathrm{cd}}$ in calcium-free MOPS buffer is significant, and renders Twitch2B inappropriate for a MEOF calcium ion monitor; the inset depicts the emission spectra normalized by mCerulean3 peak intensity. 


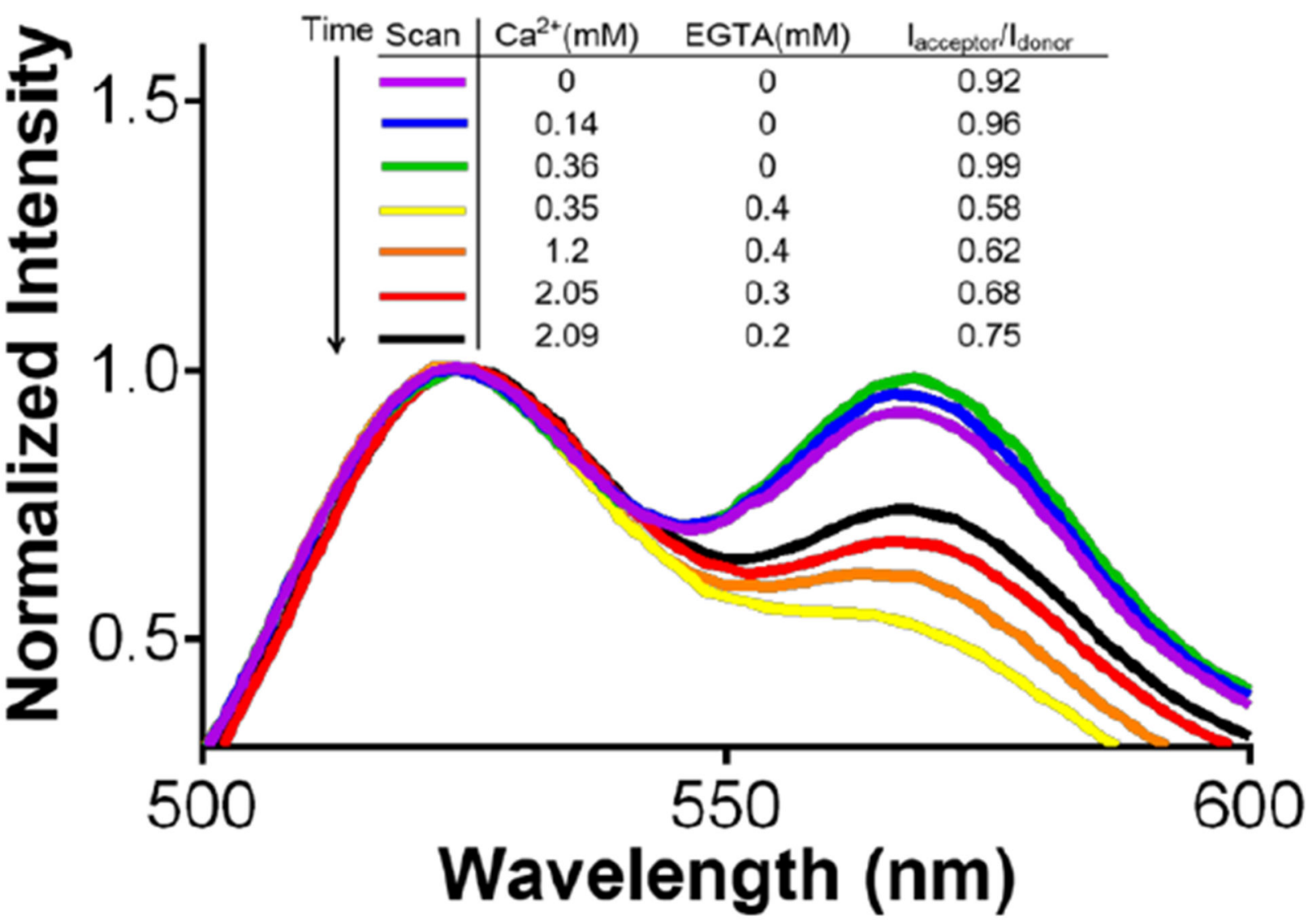

Figure 7.

STC $\mathrm{Ca}^{2+}$ response in a fluorescence plate reader normalized by Alexa Fluor 488 peak intensity. The FRET ratio response is sensitive to increasing concentrations of $\mathrm{Ca}^{2+}$. 
(A)

(C)

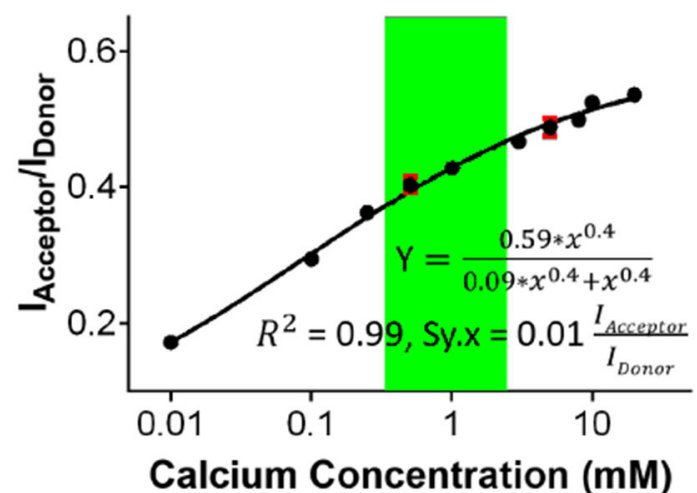

(B)

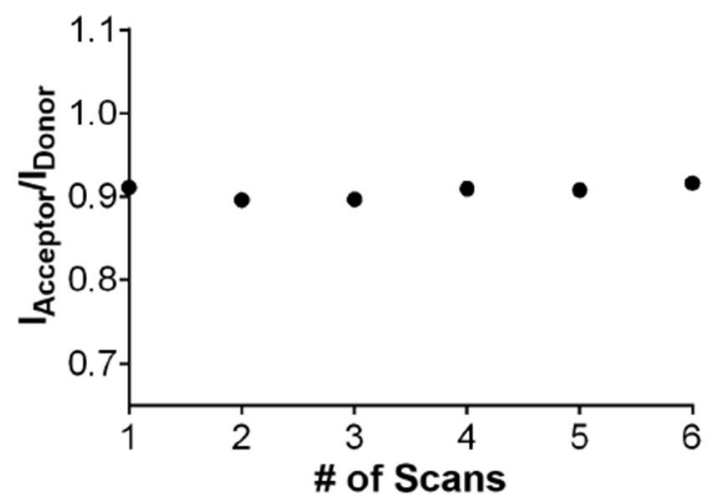

(D)
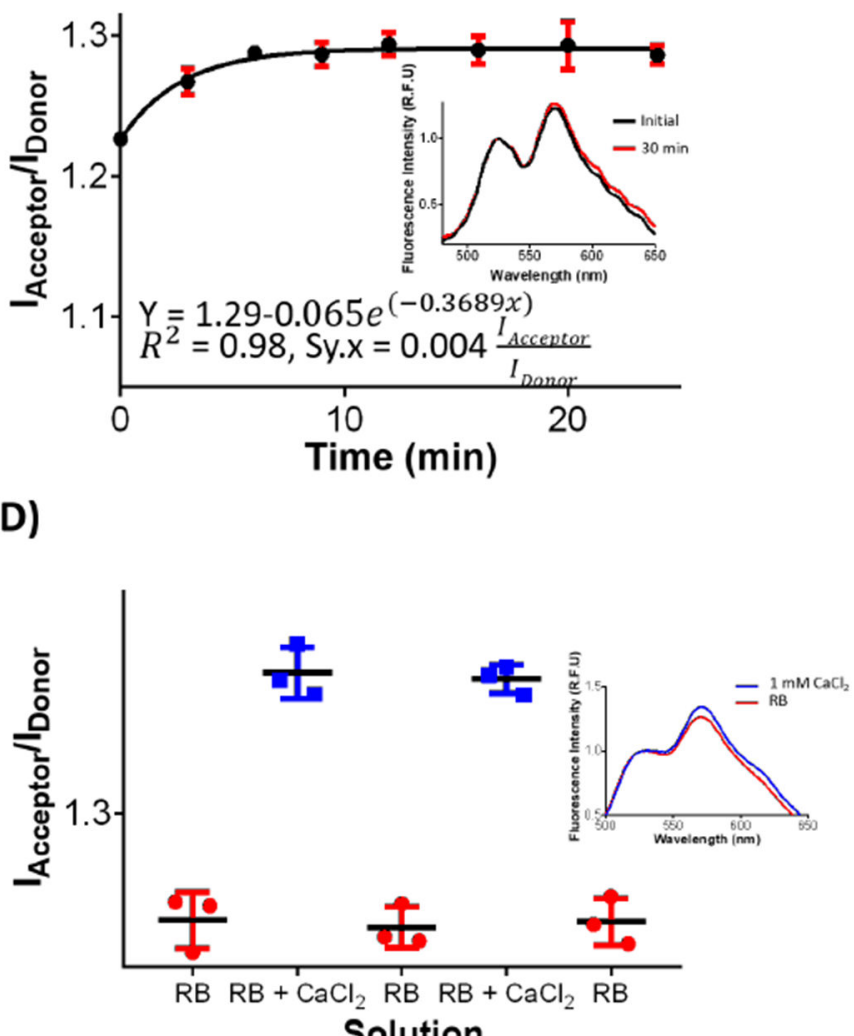

Solution

Figure 8.

$\mathrm{Ca}^{2+}$ sensing with the MEOF probe. (A) The STC exhibits excellent stability in reference buffer. (B) Steady state measurements are observed 6 min after the addition of calcium ions; the inset depicts the emission spectra normalized by donor peak intensity. (C) The STC exhibits a dose-dependent response, and the data fits to a Hill equation. $\mathrm{I}_{\text {acceptor }} / \mathrm{I}_{\text {donor }}$ is emission ratio after subtracting spectra in calcium ion-free RB. (D) The MEOF device has excellent reproducibility after serial exposures to either buffer supplemented with $\mathrm{Ca}^{2+}(1$ $\mathrm{mM}$ ) or RB. 
(A)

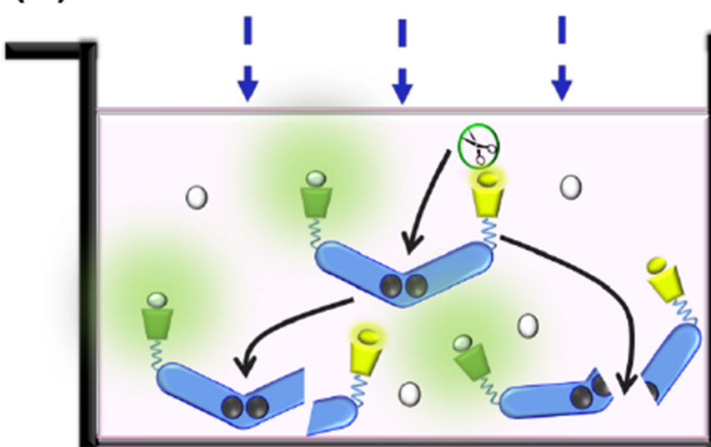

క.

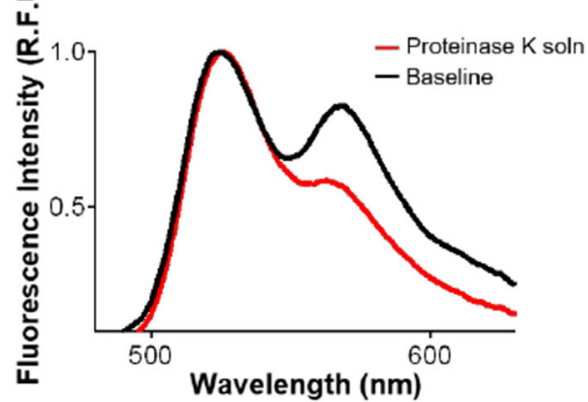

(B)

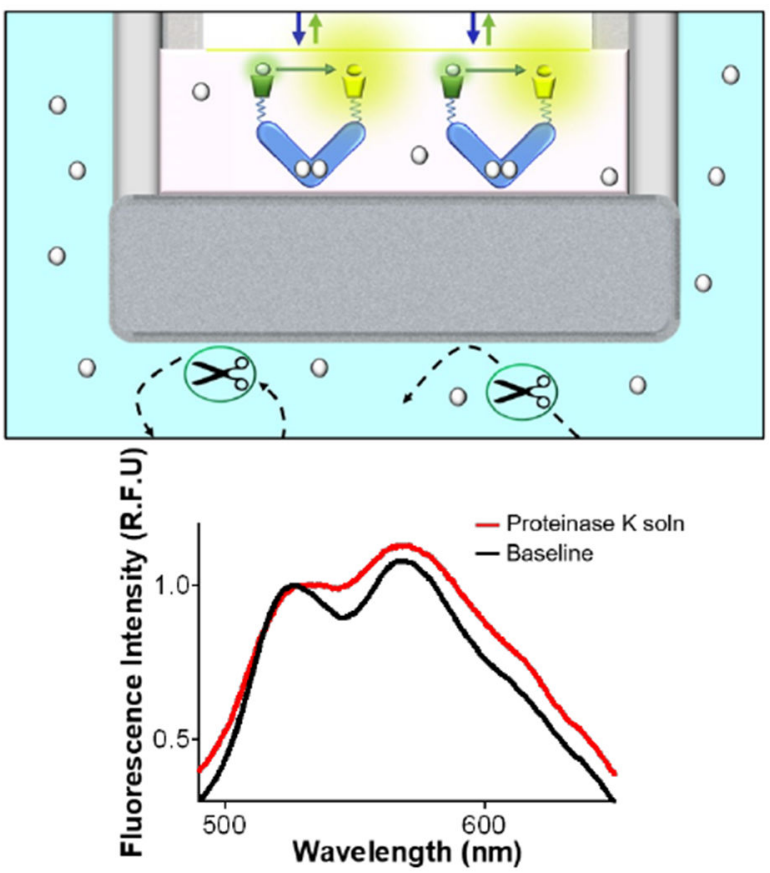

Figure 9.

Sensor Isolation from Proteinase K. (A) Proteinase K cleaves STC resulting in a diminished acceptor intensity signal. (B) However, the MEOF successfully protects the protein sensor as demonstrated by the observed increase in FRET efficiency. 